in acceleratory concentrations does not inhibit the action of dye, when both are added together with malonate.

\begin{tabular}{|c|c|c|}
\hline No accelerator & 1 DNOC $3 \times 10^{-5} \mathrm{M}$ & Pyocyanine $10^{-3} \mathrm{M}$. \\
\hline No malonate $\quad 11^{\circ} 4$ & $23 \cdot 1$ & 26.5 \\
\hline Malonate $0.01 M . \quad 8.9$ & 9.2 & $23 \cdot 8$ \\
\hline
\end{tabular}

The succinate-fumarate transformation must be involved in the respiration provoked in tumour tissue by DNOC, but not in the dye-catalysed respiration. Hence the route of carbohydrate oxidation in presence of dye, whether straight path or Krebs ${ }^{11}$ cycle, cannot include the succinate-fumarate step. From its magnitude it is unlikely that the respiration in presence of malonate and dye represents a partial oxidation, and it is probable that the oxidations stimulated by dye and DNOC do not differ qualitatively. It would follow that the succinate-fumarate change involved in the DNOC-catalysed respiration is not in the path of carbohydrate breakdown, but is concerned with a catalysis of the Szent-Györgyi ${ }^{12}$ type. Tumour tissue will not reduce oxaloacetate with any speed, either alone $\left(B r e u s c h{ }^{12}\right)$, or in the presence of glucose or glucose with $\mathrm{DNOC}^{1}$. There- fore, as Szent-Györgyi ${ }^{12}$ has suggested, the catalysis is likely to be by the succinate-fumarate, and not by the malate-oxaloacetate, oscillation. Inhibition of the DNOC-catalysed respiration of $M C 2146$ is overcome by high concentrations $(0.06 \mathrm{M}$.) of $l$-malate.

There is thus reason to suppose that, like narcotics, malonate inhibits hydrogen-transfer in a system in tumour tissue which is 'by-passed' by dyes but not by DNOC. As Szent-Györgyi ${ }^{12}$ has found that in several dehydrogenations $H$ passes to the acceptor dye through a $\mathrm{C}_{\mathbf{4}}$-acid system, the 'by-passing' observed in tumour tissue is not without interest.

${ }^{1}$ Greville, G. D., Ph.D. thesis (London, 1939).

'Michaelis, H., and Quastel, J. H., Biochem. J., 35, 518 (1941).

${ }^{3}$ Gerard, R. W., Arch. Neurol. Psychiat. (Chicago), 40, 985 (1938).

‘ Dickens, F., Biochem. J., 30, 1064 (1936).

${ }^{3}$ Cohen, R. A., and Gerard, R. W., J. Cell. Comp. Physiol., 10, 223 (1937) (table II, p. 229).

- Brewer, G., J. Pharmacol., 58, 135 (1936).

${ }^{7}$ De Meio, R. H., and Barron, E. S. G., Proc. Soc. Exp. Biol., 32,36 (1934).

${ }^{8}$ Greville, G. D., Biochem. J., 30, 877 (1936).

- Krahl, M. E., and Clowes, G. H. A., J. Biol. Chem., 111, 355 (1935).

${ }^{10}$ v. Euler, H., and collaborators, Z. Krebsforsch., 49, 46 (1939); Ark. Kemi. Mineral. Geol., 13, Nos. 6 and 8 (1939).

${ }_{11} \mathrm{Krebs}$, H. A., Biochem. J., 34, 775 (1940).

${ }^{12}$ v. Szent-Györgyi, A., "Studies on Biological Oxidation and some of its Catalysts" (Barth, Leipzig, 1937).

\title{
ACTION OF THE EYES IN READING
}

$\mathrm{B}^{\mathrm{Y}}$ $\mathrm{Y}$ using apparatus similar in principle to that of an electrocardiogram, M. Luckiesh and F. K. Moss, working at the Lighting Research Laboratory of the General Electric Company, Cleveland, Ohio, have investigated the action of the eyes in reading*. One electrode is placed in the centre of the forehead, and the other on one of the temples. The feeble electric currents produced by the eye muscles are amplified. more than a million times, and recorded photographically by an oscillograph. The currents obtained are so weak, and the instrument is so sensitive that electrical disturbances are likely to arise from other biological processes taking place in the patient's body, as well as from electro-magnetic waves induced in his body by electrical apparatus such as lamps.

Reading ordinary type an average adult reader traverses a line of print $3 \frac{1}{2} \mathrm{in}$. long in about six stages or fixations. Each shift from one fixation to the next occupies about 0.03 sec., and involves an electrical charge of the order of 0.00001 volts. One fixation comprises about nine letters. Fixations themselves vary in time from about $0 \cdot 2$ to $0 \cdot 5$ seconds. They tend to become longer towards the end of a line. If one fixation proves unsatisfactory, the suceeding one may shift backwards along the line, but it usually occupies a shorter period of time.

The remarkable control exercised by the perceptual faculties over the eye muscles is evidenced by the fact that an ordinary person reads about the same number of letters at each fixation, whether the print is in 4-, 10- or 18-point type. Between fixations visual patterns do not appear to be registered in the brain cortex, so avoiding blurring. The same is true of shifts in fixation from one line to the next, which may occupy $0 \cdot 12$ seconds, involving an electrical charge of 0.00006 volts.

* School and Society, 53, No. 1376 (1941).
The fatigue of continuous reading may be appreciated from the fact that each fixation involves the simultaneous adjustment of six separate muscles to each eye, and that both eyes must work in harmony. Each set of type characters impress a new perceptual task upon the brain, giving rise to conceptual patterns as the letters read convey their message. Records of the electrical charges taking place in the eye muscles at the beginning and end of a long period of continuous reading are not dissimilar, indicating that the muscles retain the ability to respond adequately when perceptual faculties are beginning to show signs of fatigue.

Children often make twice or three times as many fixations as an adult in reading the same amount of print. This manifests itself in the slower rate of reading, as well as in the earlier stage at which fatigue sets in.

An average educated person when reading blinks about six times a minute. Each blink occupies about $0 \cdot 3$ seconds, and the electromyogram indicates that in blinking the eyes shut much more rapidly than they open again. During the process of blinking the eyes are rotated inwards and upwards, and then out again to produce an entirely new fixation. It used to be thought that blinking merely served to keep the cornea moist and wash away foreign particles. Now it is known that blinking also helps to relieve ocular fatigue.

Recent investigations have shown that the frequency of blinking is reduced if conditions for good vision are improved, as, for example, by better illumination, by means of glasses, and by using more legible print. During periods of increased concentration blinking may be postponed until a less critical stage is reached, but only at the cost of an earlier onset of fatigue. 